\title{
EKSISTENSI PERTUNJUKAN DAN KONSEP DALAM BERKARYA SOLO BEATBOX COMMUNITY
}

\author{
Tantri Nindyas Wari \\ Alumni Mahasiswa Jurusan Etnomusikologi \\ Institut Seni Indonesia Surakarta \\ Email: tantrinin@gmail.com |085602017911
}

\begin{abstract}
The music carried by the Solo Beatbox Community has its own attraction in the form of a musical imitation of a show. Imitating the sound of musical instruments with mouth, i.e. playing music without using real musical instruments, the sound produced was almost indistinguishable to that of the original instrument. This uniqueness raises the aspects regarding the existence of the group's performances whose by all means are inseparable from the works presented to the audience. Social media plays an important role in the development of their community, from promotions to publications on the Solo Beatbox Community. In order to get their stage, the Solo Beatbox Community uses the gethok tular ('word of mouth', 'viva voice') method to facilitate their access toward the upcoming shows. Member regeneration is also one of the efforts to prevent this community from dying out. They have elements in the conceptualization of their work that is based on the type and concept of the event in question, as well as the musical trends that are popular with the public. This triggered the existence of the Solo Beatbox Community show.
\end{abstract}

Keywords: Solo Beatbox Community, The concept of creating Solo Beatbox Community.

\section{Pendahuluan}

Belakangan ini masyarakat mengenal jenis musik baru yang disebut Beatbox. Pada awalnya istilah Beatbox muncul dalam dunia Hip Hop yang populer pada tahun 1980-an. Kata "Beat Box" secara harfiah mempunyai arti ketukan (beat). Beatbox merupakan sejenis musik transmedium, yakni mampu mengalihkan suara instrumen bahkan ansamble musik dengan menggunakan mulut. Imitasi suara dengan mulut juga mempunyai kompleksitas dan kerumitan. Transmedium dengan mulut mempunyai ruang lingkup musikal yang luas, secara harmoni dan aransemen serta lainnya. Sehingga mulut merupakan kekuatan dari musik beatbox .

Kelihaian pada indera pengucap seperti mulut, bibir, lidah dan tenggorokan, serta pernafasan merupakan salah satu faktor utama dalam beatbox. Sehingga mampu menghasilkan suara-suara yang unik seperti bunyi-bunyi ritmis dan ketukan drum, instrumen musik, dan bunyi-bunyi lainnya, khususnya suara turntable. Terdapat tiga suara dasar atau beat dasar dalam beatbox yaitu: B T K (B= KickDrum/ BassDrum, $\mathrm{T}=\mathrm{HiHat}, \mathrm{K}=$ Snare Drum). Namun hal ini tidak akan terjadi ataupun terwujud apabila dalam pengaplikasiannya tidak dibantu dengan penggunaan mikrofon dan amplifikasi soundsistem, terutama jika sedang berada dalam suatu pertunjukan musik beatbox.

Di Kota Solo, beatbox mulai dikenal seiring masuknya musik hip-hop yakni sekitar tahun 2009. Munculnya musik beatbox dianggap asik oleh beberapa pemuda Kota Solo yang sampai saat ini aktif menjadi anggota komunitas beatbox yang bernama Solo Beatbox Community. Mereka mampu menirukan instrumen musik nyaris tak berbeda dengan aslinya, tentunya dengan melakukan latihan yang rajin. Solo Beatbox Community juga ingin memperkenalkan musik beatbox kepada masyarakat Kota Solo dan sekitarnya.

Keberadaan musik beatbox memunculkan daya tarik tersendiri bagi para penikmat musik 
terutama bagi mereka yang baru mengenal musik beatbox tersebut. Demi mengenalkan beatbox kepada masyarakat Kota Solo, dengan memanfaatkan sarana media sosial YouTube, Solo Beatbox Community berinisiatif membuat video tutorial dengan menggunakan bahasa Jawa yang menimbulkan dampak positif bagi mereka. Videovideo tersebut mereka unggah di akun channel YouTube mereka yang diberi nama Cah Beatbox Solo. Mereka yang digawangi oleh lima orang pemuda yaitu Helmi Adibani, Erwin Indrayana, Ignatius Raditya, Yosua Aji Nugraha, dan Andreas Dobi menjadi dikenal oleh masyarakat Kota Solo. Selain itu tawaran job untuk tampil mulai banyak, dari yang awalnya mencari job menjadi diberijob.

Solo Beatbox Community memiliki konsep pada setiap karyanya. Karya yang dimaksud bisa berupa aransemen lagu maupun repertoar milik mereka sendiri. Konsep merupakan hal yang penting dalam sebuah karya, apalagi bagi Solo Beatbox Community. Selain untuk menunjukan jati diri mereka di dunia pertunjukan juga agar karya yang dibawakan oleh mereka memiliki kesinambungan terhadap pertunjukan tempat mereka tampil.

Kesinambungan yang dimaksud yaitu antara acara pada pertunjukan yang akan berujung pada penarikan perhatian terhadap penonton, karena dalam suatu acara sudah pasti mempunyai penonton masing-masing. Sebagai contoh ketika Solo Beatbox Community berada dalam pertunjukan bertemakan keroncong, maka karya yang mereka bawakan mengusung konsep musik keroncong, agar terjadi kesinambungan dengan acara pertunjukan keroncong tersebut dengan karya milik Solo Beatbox Community dan dengan penonton. Baik penonton yang utamanya sebagai peminat dari genre keroncong itu sendiri, maupun penonton yang memang dibawa sendiri atau dikelola oleh Solo Beatbox Community atas dasar bahwa mereka sebagai penikmat musik beatbox, ataupun komunitas musik lain yang turut berapresiasi, bahkan kepada penonton yang hanya sekedar sebagai penikmat pertunjukan di kota Solo.
Dalam mengkonsep karya biasanya terdapat seorang yang dominan menjadi seorang konseptor, sebut saja Fafa. Meskipun begitu semua anggota juga turut berperan dalam mengkonsep karya mereka. Bila sebelumnya sedikit dipaparkan bahwa Solo Beatbox Community memperhatikan kesinambungan dalam karya pada pertunjukannya, terkadang mereka juga mengikuti request atau permintaan. Sehingga tak jarang karya mereka mengikuti apa yang sedang booming di pasar musik. Mengikuti pasar bukan berarti mengikuti sebagai plagiat tetapi mereka mengusung genre maupun instrumen yang sedang booming. Misalnya, ketika sedang booming musik EDM (Electronic Dance Music) maka mereka memasukan unsur EDM ke dalam karyanya, ketika sedang booming musik koplo maka mereka akan memberikan sentuhan koplo pada karya mereka.

\section{Awal Mula Terbentuknya Solo Beatbox Community}

Solo Beatbox Community dibentuk atas dasar ketertarikan beberapa pemuda di Kota Solo khususnya terhadap musik Beatbox. Komunitas ini dibentuk seiring dikenalnya beatbox di kota Solo yakni tahun 2009. Sebut saja mereka adalah Ian, Jojo, Erwindrayana, Helmi, dan Dobyyang saat itu sedang menginjak bangku SMA (Sekolah Menengah Atas). Seiring berjalannya waktu, perkembangan berupa kemajuan teknologi komunikasi dan informasi turut berperan dalam proses awal mula pembelajaran beatbox oleh Solo Beatbox Community. Perubahan terbesar dalam bidang komunikasi setelah munculnya televisi adalah penemuan dan pertumbuhan internet. Dimana saat itu anggota Solo Beatbox Community menggunakan sarana internet tersebut dalam mengeksplorasi pengetahuan dan kemampunan mereka terhadap beatbox. Internet merupakan bagian dari komunikasi digital (Severin dan Tankard, 2011:443). Secara garis besar media sosial dan jaringan sosial menggunakan sistem yang sama yaitu media daring yang terhubung dengan internet. Ketika mereka mulai memfokuskan minatnya 
terhadap musik Beatbox, yang dilakukan yakni dengan mempelajari Beatbox secara otodidak melalui media internet. Mereka menggunakan internet untuk mengakses Youtube dimana di dalamnya terdapat video-video tutorial dalam bermain beatbox yang berlanjut dengan kegiatan sharing ilmu satu sama lain.

Solo Beatbox Community bukanlah sebuah komunitas yang semata-mata langsung berdiribegitu saja tanpa alasan, terdapat banyak perjalanan dan proses hingga akhirnya komunitas beatbox di Solo ini resmi dibentuk. Sebelum membentuk Solo Beatbox Community, mereka pada awalnya membentuk grup rap diantaranya adalah Takabur, WWW (Triple W), dan Abud a.k.a Erwindrayana. Terbentuknya grup membuat mereka menjadi sering bertemu untuk sekedar nongkrong, sharing maupun beradu freestyle. Namun ketika sedang freestyle ada yang dirasa kurang oleh mereka. Dobby menjelaskan bahwa mereka merasa belum lengkap karena tidak adanya musik yang mengiringi ketika sedang freestyle (rap), karena pada umumnya Rap memang identik dengan iringan berupa musik Hip Hop selain itu Rap juga merupakan salah satu cabang dari budaya Hip Hop.

Untuk mengatasi keganjilan tersebut mulailah salah satu dari mereka yakni Erwin untuk mencoba mempelajari Beatbox yang juga merupakan cabang dari budaya Hip Hop sebagai pengganti dari alat musik Dj yang memang diperuntukan dalam pertunjukan Hip Hop yakni Rap maupun Breakdance. Dirasa tidak memerlukan banyak modal di dalamnya maka mulailah mereka menekuni Beatbox secara serius.

Perasaan nyaman terhadap musik Beatbox dan didukung dengan kemampuan yang cukup mumpuni, mulailah mereka berinisiatif membentuk sebuah grup bernama Beatboxchestra. Mereka mulai terjun dalam dunia musik dengan memilih musik beatbox sebagai fokus mereka, karena menganggap musik yang irit dalam menekuninya. Dalam hal tersebut tidak perlu mengeluarkan banyak uang untuk mengikuti sekolah khusus, dan membeli alat musik tertentu sepertihalnya dalam membentuk sebuah grup band maupun ansambel yang memerlukan instrumen seperti gitar, piano, drum, maupun instrumen lainnya. Selain itu juga tidak perlu tempat khusus dalam memainkannya, seperti menyewa studio musik karena beatbox bisa dimainkan dimana saja. Dengan mengandalkan mulut dan indera pengecap dan mempelajari beatbox dengan tekun maka para beatboxer bisa menirukan suara instrumen musik dengan semirip mungkin.

Setelah menggali potensi mereka terhadap beatbox dan melakukan pembuktiannya ditandai dengan membentuk Beatboxchestra, mereka mulai berani unjuk gigi di panggung pertunjukan. Karena saat itu mereka masih duduk di bangku SMA yakni di SMA Pangudi Luhur Santo Yosef Surakarta, mengawali aksi panggungnya dengan mendapatkan kesempatan untuk tampil di acara pertunjukan sekolah. Respon positif mereka dapatkan dari pertunjukan panggung mereka, merupakan suatu hiburan baru di sekolahan, bisa dibilang anti mainstream karena penampil biasanya merupakan group band. Semakin dikenal, semakin tinggi juga jam terbang mereka sehingga mulai banyak pertunjukan di luar yang menanti mereka. Dengan begitu semakin banyak pula peminat beatbox di kota Solo ini, maka dari itu fokus mereka menjadi berubah, dari yang awalnya merupakan sebuah grup bernama Beatboxchestra menjadi Komunitas bidang Beatbox yakni Solo Beatbox Community sekaligus menjadi komunitas beatbox tertua karena merupakan komunitas beatbox pertama di kawasan Jawa Tengah dan Jogjakarta. Tak sedikit media yang mulai meliput mereka, diantaranya adalah koran Solopos pada tahun 2013 dengan judul "Komunitas Solo Raya: Solo Beatbox Membeatbox-an Solo" pada tahun 2013, dan Solopos Tv pada tahun yang sama.

\section{Strategi Publikasi Solo Beatbox Community}

Sejak awal didirikannya Solo Beatbox Community, Dobby yang merupakan salah satu founder sekaligus anggota komunitas tersebut memiliki peran untuk memegang maupun memanagement agar SBC bisa memasuki panggung 
pertunjukan di Kota Solo khususnya. Dimulai dengan mencaripanggung kosong untuk mereka pentas yang selanjutnya dimintai ijin agar bisa menampilkan pertunjukan Beatbox oleh mereka. Hal tersebut dilakukan untuk memepertontonkan Beatbox sekaligus bertujuan agar masyarakat di Kota Solo dan sekitanya bisa mengenal beatbox sebagai hiburan panggung yang fresh. Sekaligus memperkenalkan kepada masyarakat bahwa Kota Solo mempunyai Solo Beatbox Community. Selain itu agar komunitaskomunitas lain yang sudah ada bisa mengenal komunitas Beatbox ini. Setelah mendapatkan akses ke panggung pertunjukan, strategi selanjutnya adalah memperkenalkan Solo Beatbox Community dengan memanfaatkan media sosial.

Berdasarkan pengalaman mereka ketika sedang mempelajari Beatbox, muncul kesadaran akan kurangnya media dalam pembelajaran Beatbox. Lalu munculah inisiatif dari mereka untuk membuat akun-akun media sosial seperti:

\section{YouTube}

Youtube adalah sebuah situs web untuk berbagi video yang memungkinkan penggunanya untuk mengunggah, menonton, dan berbagi video sesuai dengan konten masing-masing pengunggah yang bisa ditonton oleh semua pengguna aplikasi Youtube. Dalam akun YouTube mereka diisi konten berupa video tutorial beatbox. Video yang ada di akun You Tube Cah Beatbox Solo ini seluruhnya diproduksi sendiri oleh mereka, merangkup sebagai kreator dan pelaku tutorial beatbox yang dipost akun mereka. Sesuai dengan nama akun You Tube mereka yakni "Cah Beatbox Solo", bahasa yang digunakan dalam tutorialpun menggunakan bahasa Jawa sebagi bentuk identitas dari komunitas mereka yang berasal dari Solo yang sekaligus memberi daya tarik tersendiri bagi setiap penontonnya. Hal tersebut membuahkan respon yang positif. Terhitung hingga saat ini jumlah viewer pada setiap videonya mencapai ratusan bahkan ribuan orang walaupun bahasa yang digunakan susah dimengerti oleh orang pada umumnya.

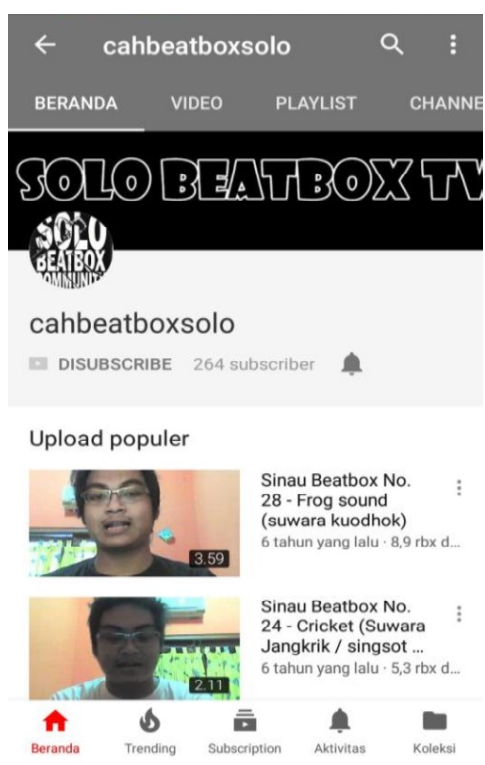

Gambar 1 : Halaman akun Youtube Solo Beatbox Community bernama CahBeatboxSolo.

(Photo : Screenshot-Wari, 2018)

\section{Twitter}

Beralih dari YouTube, media sosial lain yang digunakan sebagai sarana publikasi adalah Twitter. Sosisal media yang didirikan pada Maret 2016 ini merupakan layanan jejaring sosial dan mikroblog daring yang memungkinkan penggunanya untuk mengirim dan membca pesan berbasis teks yang dibatasi hanya sampai 140 karakter.

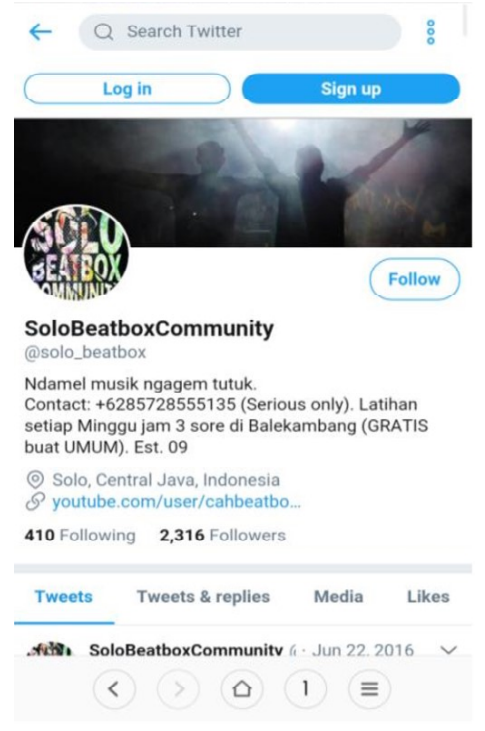

Gambar 2 : Halaman akun twitter SBC bernama @Solo_beatbox https://twitter.com/solo_beatbox (schreenshoot oleh penulis) 
Media sosisal bersimbol burung ini turut membantu proses perkenalan Solo Beatbox Community terhadap dunia luar. Melalui akunnya @Solo_beatbox dengan jumlah follower atau pengikut sebanyak 2000an ini berisikan informasi singkat mengenai SBC, jadwal event ataupun gathering dan berbagi informasi dari akun twitter komunitas lainnya.

\section{Facebook}

Masih tetap menggunakan media sosial, Youtube dan twitter dirasa kurang cukup karena memang ada banyak media sosial yang marak digunakan oleh kaum muda pada waktu itu sampai sekarang. Di dalam fanspage terdapat informasi mengenai Solo Beatbox Community terutama seputar kegiatan-kegiatan mereka, jadwal gathering, jadwal manggung, dan mengenai event-event beatbox yang akan diselenggarakan, selain itu fanspage ini juga sebagai tempat sharing seputar beatbox dan sarana diskusi mengenai beatbox. Dampak positifyang didapatkan tentu saja dengan terjalinnya komunikasi antar komunitas beatbox di luar kota Solo. Terhitung sampai saat halaman mereka disukai oleh 1,6 pengguna akun facebook.

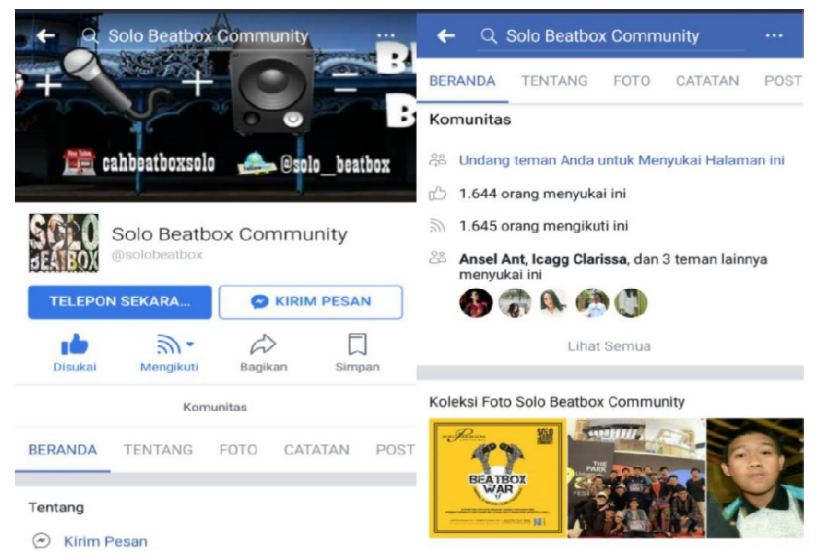

Gambar 3 : Halaman akun Facebook Solo Beatbox Community

\section{Instagram}

Media sosial paling terakhir dibuat adalah Instagram bisa dibilang media sosial ini yang sedang booming saat ini. Instagram adalah sebuah aplikasi berbagi foto dan video yang memungkinkan penggunanya mengambil foto maupun video dengan menerapkan filter efek digital pada setiap postingan dengan memberikan caption atau keterangan di setiap postingannya. Mereka baru membuat instagram setelah membuat akun YouTube, Facebook dan Twitter, dikarenakan belum mendapat adminnya pada waktu itu hngga akhirnya membuat akun instagram sekitar tahun 2016. Karena instagram merupakan media sosial yang mengharuskan penggunanya untuk menggunggah foto ataupun video, maka yang diposting adalah berupa foto-foto dari kegiatan yang sudah terselenggara, maupun pamflet dari acara yang akan berlangsung, bahkan video-video cuplikan beatbox oleh anggota SBC maupun dari beatboxer lain yang diupload ulang oleh SBC dengan caption atau keterangannya masing-masing.

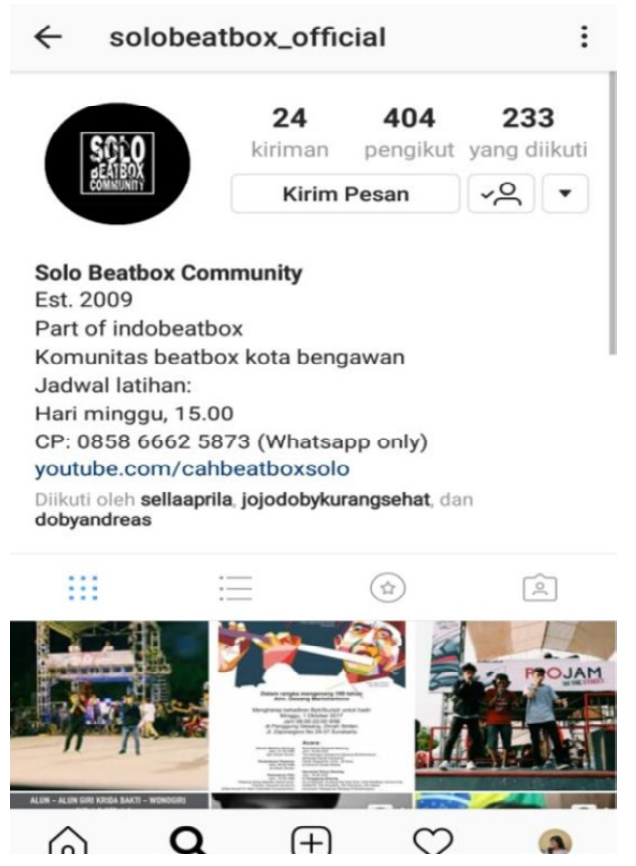

Gambar 14 : Halaman akun Instagram Solo Beatbox Community 
Media sosial dirasa sangat efektif dalam publikasi Solo Beatbox Community terhadap orang lain. Menurut Nasrullah (2015: 16-33) yang mengatakan bahwa media sosial mempunyai beberapa karakteristik, dimana dalam hal ini mampu membantu suatu komunitas untuk mengembangkan dirimelalui komunikasi media sosial, yaitu:

\section{Jaringan (Network) antar pengguna}

Media sosial terbangun dalam struktur sosial yang terbentuk di dalam jaringan atau internet. Jaringan sosial terbentuk melalui perangkat teknologi yaitu internet yang membuat jaringan antar penggunanya.

\section{Informasi (Information)}

Informasi menjadi hal utama dalam masyarakat informasi. Karakteristik informasi dapat dilihat dalam dua sisi yaitu media sosial sebagai medium yang bekerja berdasarkan informasi dan menjadi komoditas yang ada di media sosial. Bahwa media sosial merupakan salah satu wadah bagi Solo Beatbox Communityuntuk menyampaikan informasi mengenai komunitas mereka maupun informasi seputaran beatbox. Informasi yang disampaikan bisa berupa jadwal pertunjukan SBC ataupun jadwal acara Beatbox yang akan datang dalam bentuk postingan foto dan keterangan informasi pada gambar.

\section{Arsip (Archive)}

Arsip menjadi sebuah karakter yang menjelaskan bahwa informasi telah tersimpan dan dapat diakses kembali kapan saja. Solo Beatbox Community juga mengalih fungsikan sosial media untuk menyimpan beberapa dokumentasi mereka dengan cara mengunggahnya di sosial media milik mereke.

\section{Interaksi (Interactivity)}

Interaksi terbangun melalui jaringan antar pengguna. Interaksi yang terjadi dalam media sosial dapat berupa bentuk saling berkomentar atau memberikan tanda antar pengguna media sosial. Interaksi yang dimaksud adalah tidak langsung, bisa dilihat dari beberapa komentar dari beberapa pengguna sosial media yang lainnya pada postinganpostingan yang diunggah pada akun Solo Beatbox Community.

\section{Simulasi (Simulation) Sosial}

Simulasi yaitu keadaan realitas khalayak semakin berkurang dan tergantikan dengan realitas semu. Khalayak seolah-olah berada diantara realitas danilusi.

\section{Konten Oleh Pengguna (User Generated Content)}

Seluruh konten media sosial milik dan berdasarkan kontribusi pemilik akun. Konten oleh pengguna sebagai penanda bahwa media sosial khalayak tidak hanya memproduksi konten pribadi tetapi juga mengkonsumsi konten yang dimiliki oranglain. Tentu saja konten pada akun milik Solo Beatbox Community adalah konten musik beatbox, dimana didalamnya berisi mengenai tutorial dan informasi mengenai beatbox baik dari dalam maupun luar komunitas mereka. Media sosial berbasis internet yang berperan sebagai sumber informasi yang jaringannya tersebar hingga ke seluruh dunia.

Media sosial membuat manusia lebih transparan dalam berkomunikasi, dan aktivitas setiap orang dengan mudah dapat diketahui orang lain, bahkan seluruh dunia (Nurrudin, 2013: 84). Media sosial merupakan sebuah alat dan kebutuhan bagi manusia untuk berbagi berbagai macam informasi, berita, opini, fakta, dan berbagai macam pesan yang ingin disampaikannya.

Pada dasarnya media sosial merupakan perkembangan mutakhir dari teknologi yang memudahkan manusia untuk saling berkomunikasi, berpartisipasi, saling berbagi dan membentuk sebuah jaringan secara online. Dunia media sosial hadir dalam media komunikasi konvensional karena kemudahannya terhubung ke berbagai orang di belahan dunia dengan cepat dan tanpa batas.

Bentuk Pertunjukan Solo Beatbox Community Sebagai Front Stage Presentation

Pertunjukan Solo Beatbox community dimulai dengan freestyle sebagai intro. Selain sebagai 
pembuka, fungsinya untuk menghangatkan suasana sebelum mulainya pertunjukan. Bagi anggota Solo Beatbox Community bisa juga berfungsi untuk check sound ulang, selain itu bisa untuk menyesuaian beat sebelum pertunjukan utama dimulai, juga untuk menyesuaikan $\mathrm{mood} /$ suasana hati.

Perlunya penyesuaian beat, agar ketika pertunjukan berlangsung tidak terjadi ketidakselarasan dalam tempo, dengan kata lain untuk mengantisipasi terjadinya kesalahan-kesalahan di luar teknik yang bisa terjadi ketika pertunjukan sedang berangsung. Sedangkan penyesuaian mood sangat diperlukan agar semua pemain mampu membawakan pertunjukan dengan mood yang baik, begitu halnya jika terjadi mood yang buruk sebelumnya bisa menjadinetral atau baik kembali. Tidak hanya untuk pemain saja tetapi untuk penonton agar saat pertunjukan berlangsung pemain dan penonton bisa lebih antusias.

Untuk menarik perhatian penonton, para penampil biasanya memainkan efek suara tertentu untuk memusatkan perhatian penonton. Misalnya tiba-tiba saja memainkan efek suara robot, hal tersebut mampu menjadi salah satu faktor untuk penonton tidak melewatkan pertunjukan beatbox dari Solo Beatbox Community. Hal itu berlanjut ke freestyle, masih dalam konteks sajian pembuka pertunjukan mereka. dalam freestyle-nya biasanya mereka memainkan beat yang cenderung kencang dan bertempo cepat agar suasana lebih hangat dan meningkatkan kepercayaan diri para pemain. Selain itu dapat meningkatkan antusiasme dari para penonton.

Berlanjut ke perkenalan, sebelum penampil memperkenalkan diri, akan terlebih dulu ada seseorang anggota yang memperkenalkan komunitas mereka yakni Solo Beatbox Community. Jojo dan Ian biasanya bertugas sebagai juru bicara pada masanya. Dalam hal ini hanya memperkenalkan SBC secara garis besar kepada penonton, dan berlanjut pengenalan anggota yang akan melakukan perform. Ketika perkenalan, tak jarang juga ketika ada seorang pemain yang sedang berbicara ada pemain yang sedikit memainkan beatbox dengan volume lebih kecil seolah menjadi backsound, agar penonton juga tidak merasa bosan dengan perkenalan tersebut.

Setelah menyuguhkan intro dan perkenalan dari komunitas juga pemain, masuklah mereka ke pertunjukan yang sebenarnya atau bisa disebut dengan pertunjukan utama. Jika sebelumnya mereka melakukan freestyle yang cenderung merupakan improvisasi, berbeda dengan pada pertunjukan utama. Disini mereka mulai memainkan beberapa lagu utuh maupun medley lagu sesuai dengan arransemen yang sudah dibuat. Mereka memainkan lagu-lagu maistream, seperti lagu populer, maupun lagu yang sedang naik daun. Aransemen yang digunakanpun beragam, tidak hanya satu genre saja. Bahkan efek suara yang diberikanpun bisa menyesuaikan pasar yang ada, misalnya memberikan efek suara musik Dj ketika sedang maraknya musik EDM. Tak hanya menunjukan skill beatbox, tak jarang juga mereka menunjukan teknik tertentu yang tidak lazim, seperti menghasilkan suara menggunakan tenggorokan dalam yang akan menarik perhatian para penonton.

\section{Upaya Solo Beatbox Community dalam Mempertahankan Eksistensinya di Panggung Pertunjukan Musik}

Jika sebelumnya Solo Beatbox Community menggunakan kekuatan sosial media sebagai sarana dalam mempublikasikan komunitasnya, berbeda dengan upaya yang dilakukan untuk mempertahankan eksistensi mereka dalam dunia panggung pertunjukan musik yakni dengan menggunakan kekuatan hubungan antar komunitas. Dengan kata lain bahwa suatu komunitas mampu menjalin hubungan baik dengan komunitas yang lainnya. Hal tersebut bisa memberi keuntungan tersendiri bagi masing-masing komunitas. Biasanya bisa disebut sebagai Community relation menurut Wilbur J.Peak yang dimuat dalam Lesley s Public Relations Handbook dan diterjemahkan oleh Onong U.Effendy mendefinisikan hubungan dengan komunitas sebagai berikut: "Hubungan dengan komunitas sebagai fungsi hubungan masyarakat, merupakan partisipasi suatu lembaga yang 
berencana, aktifdan berkesinambungan dengan dan di dalam suatu komunitas untuk memelihara dan membina lingkungannya demi keuntungan kedua pihak, lembaga dan komunitas." Jadi tidak menutup kemungkinan untuk menjalin relasi dengan komunitas lain, seperti halnya komunitas Solo Beatbox Community yang berelasi dengan komunitas musik lain diluar beatbox sebut saja Solo Blues Rock, komunitas musik metal, komunitas musik hip-hop dan yang lain.

Eksistensi merupakan hal yang penting bagi setiap komunitas, karena melalui ekstistensi keberadaan suatu komunitas sosial akan langgeng dan diakui keberadaanya. (Skripsi Eka UNY). Dalam memepertahankan eksistensi Solo Beatbox Community di pertunjukannya, upaya yang dilakukan adalah dengan menggunakan metode Getok tular. Istilah tersebut tidak asing bagi orang Jawa, artinya adalah menginformasikan sesuatu dari mulut ke mulut. Dengan menjalin relasi antar komunitas lain, dan menjalin pertemanan dengan masing-masing anggotanya, maka mudah untuk menerapkan getok tular ini. Istilah getok tular dalam bahasa Jawa berasal dari kata getok dan tular. Getok dalam istilah Jawa merupakan kata kerja yang berarti mengetuk atau memukul, sedangkan tular artinya menjalar atau merembet yang sama artinya dengan menular. Getok tular maksudnya adalah mengetuk atau memukul secara menjalar. Ibaratnya sebagai berikut, ada seseorang sedang memukul sesuatu, lalu orang lain mengikuti hal yang serupa.

Istilah getok tular bisa digunakan untuk merujuk sistem pewarisan kelisanan dalam folklor. Dongeng, legenda, mitos, dan semacamnya pada umumnya ditularkan lewat getok tular. Riwayat suatu komunitas kecil pedesaan kerap kali tidak diketahui secara pasti lantaran langka data tertulis sehingga, seperti ditulis oleh Paul Thompson dalam The Voice of the Past (2000), sangat mengandalkan "suara-suara kelampauan" yang tak terekam. Sampai di sini istilah getok tular terkesan hanya berkaitan dengan budaya tradisional yang sering mendapat cap "primitif'. Namun, istilah forward menandakan ada sarana praktik getok tular dalam komunikasi modern.
Bahasa Inggris menyulih getok tular menjadi word of mouth (WOM) seperti dalam buku Jerry R Wilson, Word-of-Mouth Marketing (1994). Terbaca dalam judul itu, WOM dimanfaatkan untuk pemasaran. Disebutkan, WOM merupakan teknik komunikasi pemasaran terampuh untuk "mengharumkan atau merusak citra". Dalam kasus Solo Beatbox Community, getok tular ini dijadikan secara tidak sengaja memperkenalkan SBC di kalangan kelompok musik lain dengan memberikan kesan yang baik agar bisa disebarluaskan kembali oleh kelompok lain.

Cara konkritnya yakni menjadi apresiator bagi komunitas lain yang nantinya juga akan meningkatkan jalinan hubungan yang baik antar komunitas yang ada, selain itu bisa juga menjadi sarana untuk menunjang ke-eksistensian suatu komunitas. Sebagai contoh, anggota komunitas Solo Beatbox Community mendatangi pertunjukan yang diadakan oleh sebuah komunitas, dari apresiasi tersebut bisa menjalin suatu hubungan dengan komunitas lain disitu komunitas lain menjadi tahu bahwa di Solo ada yang namanya komunitas beatbox yakni Solo Beatbox Community.

Selain menggunakan metode Getok Tular, Regenerasi juga merupakan salah satu faktor yang bisa mempertahankan eksistensi pertunjukan Solo Beatbox Community hingga sekarang. Regenasi menurut KBBI adalah penggantian generasi tua kepada generasi muda. Hal tersebut dilakukan karena adanya kepentingan lain yang menjadikan prioritas utama para anggota sehingga sudah tidak bisa aktif seperti awalmula mereka membentuk komunitas ini. Beberapa founder saat inijustru tidak mejadi member aktif di SBC, dikarenakan kepentingan maupun pekerjaan yang membuat mereka tidak bisa aktif lagi, sebagai contoh adalah kendala jarak dan waktu karena bekerja di luar kota. Sebut saja Ian yang dulunya merupakan founder komunitas ini, ia dulu merupakan member aktif dan personil inti dalam pertunjukan mereka. Namun dikarenakan pekerjaanyanya yang berada di luar kota menyebabkannya tidak bisa aktif lagi. Begitu juga dengan beberapa founder lain seperti Erwindrayana dengan alasan yang sama. 
Namun bukan berarti tidak ada nama-nama lama dalam komunitas tersebut, sebut saja Dobby, Jojo, dan Vava mereka masih aktif walaupun hanya untuk sekedar memantau. Bahkan Dobby dan Jojo cenderung aktif di kegiatan Beatbox di luar SBC, yakni menjadi $\mathrm{MC}$ dalam beberapa acara gathering ataupun battle beatbox di Solo maupun Jogja. Vava saat ini masih menjadi member aktif sekaligus personil inti dalampertunjukan mereka. Dikarenakan para pendahulunya memiliki fokus dan kesibukan masing-masing, maka regenerasi yang merupakan salah satu upaya agar Solo Beatbox Community tidak hilang begitu saja. Agar masih tetap bisa eksis baik sebagai komunitas musik di Solo dan tentunya eksis di panggung pertunjukan musik maupun beatbox di Solo dan sekitarnya.

\section{Proses Pengkonsepan Solo Beatbox Community dalam Karyanya}

Bahasan selanjutnya adalah mengenai proses pengkonsepan karya oleh Solo Beatbox Community. Konsep yang sudah ditentukan melalui beberapa pertimbangan di atas dilanjutkan dengan tahap selanjutnya yakni memproses apa yang sudah didiskusikan menjadi sebuah konsep yang akan dijadikan karya oleh mereka. Proses ini juga bisa dikatakan sebagai peroses kreatif Solo Beatbox Community. Dalam proses pengkonsepan karya ini akan muncul jawaban-jawaban dari beberapa pertanyaan-pertanyaan yang dibuat sebelumnya menjadi sebuah kerangka konsep, yakni:

\section{Jumlah Lagu yang akan dibawakan.}

Pada bagian ini ditentukan berdasarkan durasi yang sudah diberikan dan ditentukan oleh sie acara dari event yang bersangkutan. Misalnya durasi yang diberikan 20menit, maka jumlah lagu yang akan dibawakan kira-kira ada dua atau tiga judul lagu yang masing-masing lagu berdurasi 5 menit. Penentuan jumlah lagu/karya tersebut sudah diperkirakan dengan perkenalan yang harus mereka tampilkan sebelum masuk ke pertunjukan beatbox. Jadi ketika Solo Beatbox Community menentukan dua lagu dengan masing-masing durasi selama 5menit, sedangkan durasiyang diberikan oleh panitia
20 menit, maka mereka masih punya waktu 10menit yang bisa digunakan sebagai warming up, perkenalan, maupun improvisasi ketika sedang berlangsungnya pertunjukan.

\section{Lagu-lagu yang akan dibawakan.}

Pada bagian ini ditentukan berdasarkan kesepakatan dari masingmasing pemain, bisa juga berdasarkan jenis event. Selain itu bisa berdasarkan judul-judul lagu yang sedang tren saat di pasar musik kalangan masyarakat. Sebagai contoh, ketika mereka akan mengisi event musik keroncong, maka mereka akan membawakan lagu keroncong, opsi lainnya adalah mereka akan mengaransemen beberapa lagu populer menjadi bernuansa keroncong. Contoh lain, jika mereka akan mengisi event di luar genre tertentu, bisa jadi lagu yang akan mereka bawa merupakan lagu yang sedang ngetrend di masyarakat, sebagai contoh adalah lagu Sayang milik Via Valen yang akan mereka sajikan dengan beatbox.

\section{Bentuk aransemen dalam lagu yang akan dibawakan.}

Sedangkan pada bagian ini bentuk aransemennya bisa dilihat berdasarkan jenis event dan konsep dari event terkait. Misalnya terdapat suatu event dimana mereka harus menjadi salah satu pengisi di dalamnya, sebagai bintang tamu, sebut saja event musik keroncong. Maka mereka akan mengkonsepkan karya mereka menjadi sebuah karya yang berunsur keroncong, maupun membawakan lagu keroncong dengan aransemen beatbox. Setelah mendiskusikan tiga hal di atas, masuklah Solo Beatbox Community ke tahap selanjutnya yakni pada tahap proses pengkaryaan.

\section{Kesimpulan}

Eksistensi Pertunjukan Solo Beatbox Community tak lepas daripenggunaan sosial media. Melalui sosial media SBC dapat mempublikasikan keberadaan kelompok mereka kepada masyarakat, hingga akhirnya kelompok tersebut bisa berkembang menjadi sebuah komunitas Beatbox di kota Solo. 
Selain mempublikasi perihal komunitas mereka yang mempunyai ketertarikan terhadap beatbox, SBC memanfaatkan fungsi dari sosial media dengan baik. Mereka menggunakan sosial media sebagai wadah untuk memperlihatkan karya mereka (berupa video tutorial di You Tube). Hal tersebut turut sebagai pembuktian bahwa SBC bukan hanya komunitas penikmat, tetapi juga sebagai pelaku musik tersebut.

Eksistensi pertunjukan SBC berlanjut melalui ajang pertunjukan musik yang ada Solo dan sekitar. Pertemuan SBC dengan grup musik berbeda genre justru menambah koneksi bagi mereka di panggung pertunjukan. Event-event di bidang beatbox mulai bermunculan dan menambah pengalaman pertunjukan bagi SBC. Berbagai macam event yang mengundang SBC itulah yang menjadikan SBC membuat konsep dalam setiap pertunjukannya.

Konsep dalam Berkarya Solo Beatbox Community menjadi pemicu eksistensi mereka di pertunjukan. Mereka selalu memeprsiapkan konsep sesuai dengan acara yang terkait. Konsep event yang bersangkutan, jenis event yang bersangkutan menjadi pertimbangan bagi mereka dalam membentuk konsep suatu karya baik aransemen maupun repertoar. Mampu mengikuti tren musik di pasaran, mampu membawakan berbagai genre dengan teknik beatbox yang mereka punya. Sehingga pertunjukan mereka menciptakan suasana baru disetiap pertunjukannya. Hal ini jugalah yang menjadi salah satu yang bisa mempertahankan eksistensi pertunjukan Solo Beatbox Community hingga sekarang. Dari dua hal tersebut bisa disimpulkan kembali bahwa eksistensipertunjukan Solo Beatbox community tidak lepas dari event-event yang diadakan oleh pihak terkait, tidak terbatas pada satu jenis genre. Koneksi melalui pertemanan memudahkan mereka untuk berada di suatu panggung pertunjukan. Semakin banyak panggung semakin eksis pula mereka. Untuk mengembangkan ke-eksistensian mereka di panggung pertunjukan. Konsep yang diciptakan pada tiap pertunjukan juga menjadi salah satu pemicu eksisteni pertunjukan bagi mereka.

\section{DAFTAR PUSTAKA}

Denis Setiaji (2015) dalam skripsinya yang berjudul "Dongkari: Konsep, teknik, dan Ornamentasi Tembang Sunda Cianjuran.

Eka Yuliana (2014) dalam skripsinya yang berjudul "Strategi Mempertahankan Eksistensi Komunitas Virginity Yogyakarta."

Getok Tular|Kasijanto Satrodinomo dalam https:// rubrikbahasa.wordpress.com/2013/10/ 19/getok-tular/ diunduh pada 19 Okt 2013.

Imam Taufik (2012) yang berjudul "Band Indie Reggae Samalona Surakarta, kajian pengelolaan organisasi dan kreativitas musikal."

Rifiana Abdul Razzak (2013) dalam skripsinya yang berjudul "Kreativitas Musik Kelompok Beatbox Community of Semarang."

\section{DAFTAR NARASUMBER}

Andreas Dhiwangkara (27th), selaku founder dan anggota Solo Beatbox Community (masih aktif di komunitas sebagai pendamping).

Jhosua Adi Nugraha (26th), selaku founder dan anggota Solo Beatbox Community (masih aktif di komunitas sebagai pendamping).

Ian Raditya (26th), selaku founder dan anggota Solo Beatbox Community (sekarang sudah tidak aktif sebagai member dan penampil).

Vava Yosalva (24th), selaku founder dan anggota Solo Beatbox Community.

Farid Hadi (22th), selaku anggota Solo Beatbox Community. 